Patrícia Stocco BETIOL ${ }^{1}$ Juarez Pinto Fernandes TÁVORA ${ }^{2}$

Andrea Cristina PARRA ${ }^{1}$

Maria Cláudia Araripe

SUCUPIRA ${ }^{1}$

Lilian GREGORY ${ }^{1}$

\begin{abstract}
Correspondência para:
Patrícia Stocco Betiol - Faculdade de Medicina Veterinária e Zootecnia da Universidade de São Paulo, Departamento de Clínica Médica, Av. Orlando Marques de Paiva, 87, Cep 05508-000, São PauloSP, psbetiol@usp.br
\end{abstract}

Recebido para publicação: 23/01/2007 Aprovado para publicação: 29/05/2008

\title{
Determinação sérica de colesterol e triglicérides em cavalos soroprodutores alimentados com concentrados com teores de $15 \%$ ou $22 \%$ de proteína bruta
}

\author{
1 - Faculdade de Medicina Veterinária e Zootecnia da Universidade de São Paulo, \\ São Paulo - SP \\ 2 - Seção de Obtenção de Plasma-hiperimune do Instituto Butantan, São Paulo - SP \\ e Universidade Federal da Bahia, Salvador -BA
}

\begin{abstract}
Resumo
A produção de soro-hiperimune em eqüinos ainda é fundamental para obtenção do soro utilizado no tratamento de algumas enfermidades como o tétano e a difteria. Para verificar o possível benefício da utilização de concentrados hiperprotéicos na dieta dos cavalos soroprodutores da Fazenda São Joaquim do Instituto Butantan-SP, foram analisados os teores séricos de colesterol e triglicérides de 32 animais, pertencentes ao plantel de produção de soro antidiftérico. Estes foram distribuídos, ao acaso, em dois grupos de 16 eqüinos. Os animais do grupo A receberam concentrado com $15 \%$ de proteína bruta (PB) e os animais do grupo B receberam concentrado com $22 \%$ de PB. As amostras de soro foram obtidas em dois ciclos de produção nos momentos anteriores à inoculação do antígeno, antes das sangrias de produção e nos dias 15, 30 e 45 de descanso. As concentrações de triglicérides foram maiores no grupo B no dia 58 do primeiro ciclo $(\mathrm{p}<0,001)$ e, no segundo ciclo, foram maiores no grupo A nos dias 95 e $137(\mathrm{p}<0,04)$ e no grupo B no dia 109 ( $\mathrm{p}<0,04)$. Não houve diferença entre os grupos para as concentrações séricas de colesterol. Este trabalho concluiu que embora as concentrações séricas de triglicérides e colesterol sejam sensíveis ao processo de produção de plasma-hiperimune antidifitérico, os resultados encontrados não foram suficientes para afirmar se há benefício ou não na utilização de concentrado hiperprotéico (22\% PB) em cavalos produtores de soro-hiperimune anti-difteria em dois ciclos de produção.
\end{abstract}

Palavras-chave:

Cavalo soroprodutor.

\section{Introdução}

Os Órgãos de pesquisa e as indústrias de medicamentos têm contribuído muito para o desenvolvimento de novas drogas para o combate de muitas enfermidades, porém para determinados microorganismos e toxinas o tratamento com maior eficácia ainda se baseia na terapia com soroshiperimunes.

A espécie animal amplamente utilizada para a produção de soro-hiperimune é a eqüina devido à sua docilidade e principalmente ao modo uniforme de reagir aos antígenos inoculados, à inserção longa e superficial das veias jugulares, facilitando as sangrias; à volemia que o eqüino apresenta, até $11 \%$ de seu peso e ao pequeno grau de toxicidade de sua albumina sérica. ${ }^{1}$

Para melhorar a eficiência produtiva de soros-hiperimunes, muitas pesquisas têm sido realizadas com adjuvantes, toxinas ou componentes de microorganismos utilizados durante o processo de produção, porém nenhuma pesquisa com relação à alimentação de cavalos soroprodutores foi realizada na tentativa de melhorar o desempenho destes animais na produção de soros. Também não existe um consenso em relação ao teor de proteínas que deva ser administrada na dieta 
destes animais.

As dietas de animais de companhia, produção e esporte, têm sido estudadas e aprimoradas, porém o incremento de proteína na dieta de animais principalmente dos que praticam atividades esportivas é controverso. Existe um raciocínio de que os animais que realizam atividades físicas necessitam de incremento protéico na dieta, porém esta hipótese não foi ainda comprovada. ${ }^{2,3,4}$

A idade, a gestação, a lactação, e a atividade do eqüino são considerações muito importantes para a determinação das exigências protéicas destes animais. ${ }^{5} \mathrm{Um}$ cavalo adulto pesando aproximadamente $400 \mathrm{~kg}$ necessita para a sua manutenção de uma ingestão diária em torno de $7,2 \%$ de proteína bruta. ${ }^{6,7} \mathrm{~A}$ indústria de alimentos tem fornecido, através do concentrado, entre $12 \%$ e $15 \%$ de proteína bruta, excedendo os valores recomendados pela National Research Council (NRC). ${ }^{2,8,9}$ Estudos realizados por Gallagher, Leech e Stowe ${ }^{10}$ demonstraram que os eqüinos da região do Michigan, nos Estados Unidos da América (EUA), têm ingerido uma concentração de proteínas nos concentrados comerciais acima do preconizado pela NRC. Na região da Carolina do Norte, também nos EUA, realizou-se outro estudo demonstrando que aproximadamente $70 \%$ dos cavalos desta região estavam sendo alimentados com excesso de proteínas fornecidas em concentrados comerciais. ${ }^{11}$

Existe grande preocupação por parte dos pesquisadores com relação aos efeitos adversos que altas concentrações de proteína na dieta podem ocasionar. ${ }^{12}$ Só existe um estudo envolvendo animais soroprodutores e concentrações de frações lipídicas, especificamente o colesterol, sem considerar a dieta do animal.

O presente estudo objetivou determinar a influência, nas concentrações séricas de colesterol e triglicérides, de dietas contendo 15 ou $22 \%$ de proteína bruta, fornecidas aos cavalos soroprodutores do Instituto Butantan e, as possíveis alterações que o processo de produção de plasma- hiperimune causa nestas variáveis.

\section{Material e Método}

Foram selecionados 32 eqüinos soroprodutores de soro-antidiftérico, hígidos, machos, castrados, sem raça definida e com idade entre seis e 12 anos, distribuídos ao acaso em dois grupos de 16 cavalos. Um grupo foi alimentado com concentrado contendo $15 \%$ de proteína bruta (PB) (Grupo A), e o outro com teor de $22 \%$ de PB (Grupo B). A principal fonte de PB de ambas dietas era farelo de soja (proteína vegetal). O fornecimento de água e volumoso foi o mesmo para ambos os grupos experimentais, imunizados com toxina diftérica e submetidos às sangrias de produção. Antes do início da pesquisa, os animais do grupo A foram submetidos a um período de adaptação de um mês com uma ração com 15\% de PB. Para a produção de soro antidiftérico, utilizou-se o processo tradicional e rotineiro da Seção de obtenção de plasma-hiperimune do Instituto Butantan.

Cada ciclo de produção dos eqüinos, do grupo produtor de soro antidiftérico, consistiu de três inoculações de antígeno e três sangrias de produção, seguidos de um período de 45 dias de descanso.

As amostras de sangue dos eqüinos utilizadas para obtenção de soro e para a realização dos testes, foram colhidas por venopunção jugular com agulhas descartáveis (25mm x $0,8 \mathrm{~mm})$, utilizando-se tubos de vidro transparentes, especiais para colheita de sangue com aspiração a vácuo, esterilizados, siliconizados, sem anticoagulante, com tampa de borracha. ${ }^{13}$ Foram colhidas as amostras de sangue dos animais antes das inoculações de antígeno, antes das sangrias de produção e durante o período de descanso dos animais, que ocorreu nos dias 15, 30 e 45 após a última sangria de produção. A pesquisa durou dois ciclos de imunização, que foram denominados fases. A primeira fase correspondeu ao primeiro ciclo e compreendeu três inoculações de antígeno (dias 1, 9 e 15), três sangrias de produção (dias 23, 25 e 28), e 15, 30 e 45 dias de 
descanso (respectivamente dias 43, 58 e 73). A segunda fase também compreendeu três inoculações de antígeno (dias 95, 103 e 109), três sangrias de produção (dias 117, 119 e 122) e 15,30 e 45 dias de descanso (respectivamente dias 137, 152 e 167).

A determinação dos teores séricos de colesterol baseou-se no método enzimático colorimétrico descrito por Allain et al. ${ }^{14}$, através de kit enzimático da Bio Systems código M 11505c-0013, no analisador bioquímico automático LIASYS ${ }^{\circledR}$, Liasys-AMSAnalysador Medical Sistem. Os teores séricos de triglicérides foram quantificados conforme técnica descrita por Fossati e Prencipe ${ }^{15}$, através de kit enzimático da Bio Systems código M 11528c-0010, no analisador bioquímico LIASYSâ.

Para a análise dos resultados foi utilizado o programa estatístico Minitabâ Release 14.1. ${ }^{16}$ Todos os valores das variáveis avaliadas foram submetidos ao teste de Anderson-Darling para determinar o tipo de distribuição dos dados. $\mathrm{Na}$ análise entre os grupos, os valores que apresentaram distribuição normal foram avaliados através do teste $T$ para duas amostras, e os que não apresentaram distribuição normal foram avaliados através do teste MannWhitney. Com relação à análise intragrupos utilizou-se o teste $T$ pareado para os valores com distribuição normal e o teste de
Wilcoxon para os que não apresentaram distribuição normal, com nível de significância $\mathrm{p}<0,05 .{ }^{17,18}$

\section{Resultados e Discussão}

Os valores médios de colesterol, embora sempre dentro dos valores considerados normais para a espécie ${ }^{19}$ (de 1,914 a 4,662 mmol/L), oscilaram durante toda a pesquisa com tendência a diminuir para ambos os grupos A e B (respectivamente $\mathrm{p} 0,04$ e $\mathrm{p}<0,03$ ) durante os períodos de imunização e sangria de produção, principalmente na primeira fase e a aumentar no período de descanso dos animais (grupos A e B p $<0,0001$ ) (Figura 1), discordando dos resultados da pesquisa realizada por Sahal et al..$^{20}$ que avaliaram as concentrações de colesterol em cavalos soroprodutores inoculados com toxina tetânica, concluindo que os valores médios de colesterol dos animais aumentaram após as imunizações. Essa discordância de resultados pode estar relacionada a fatores diferenciais entre os animais da pesquisa de Sahal et al. ${ }^{20} \mathrm{e}$ do presente estudo quanto ao tipo de antígeno inoculado, ao protocolo de imunização, ao esquema de descanso dos animais e ao tempo de utilização dos animais em produção.

Entretanto, Sahal et al. ${ }^{20}$ afirmaram que, durante o estudo, alguns cavalos

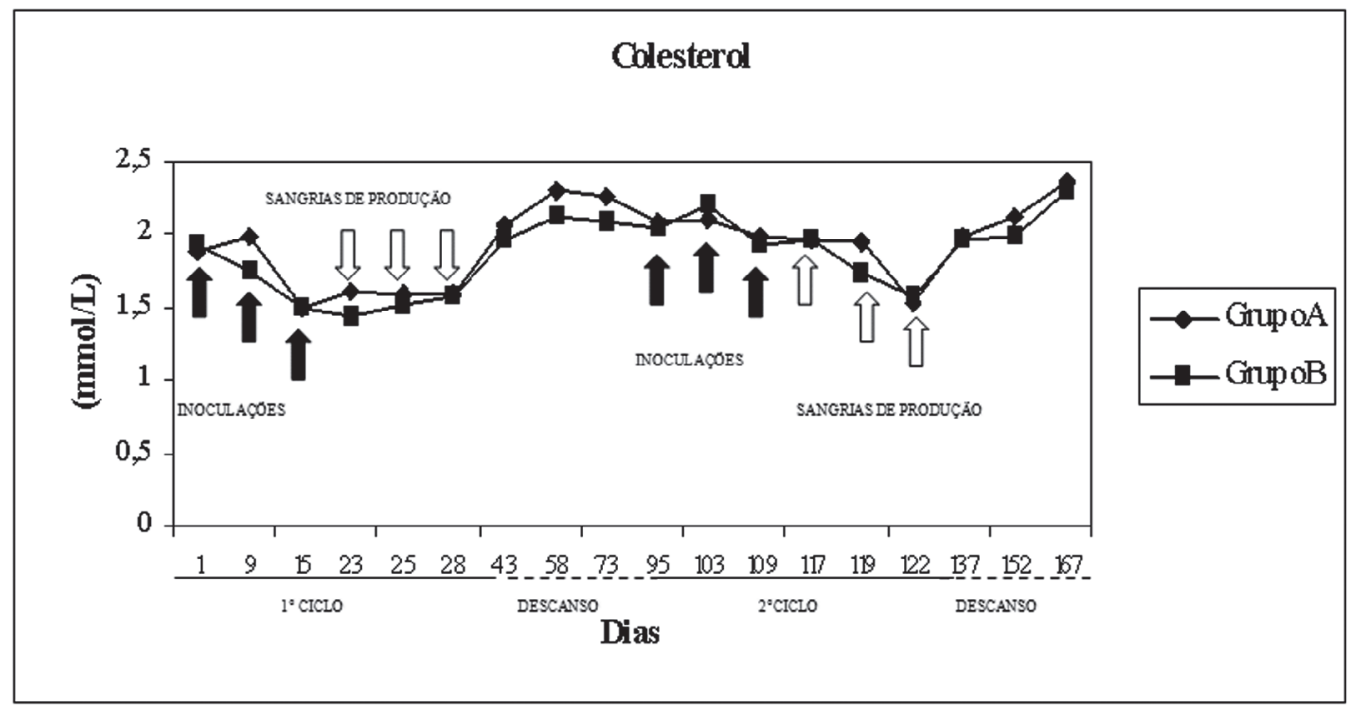

Figura 1 - Representação gráfica das concentrações séricas de colesterol dos grupos A (concentrado com 15\% de proteína bruta) e B (concentrado com $22 \%$ de proteína bruta) 
apresentaram diminuição das concentrações de colesterol, sugerindo que estes desenvolveram hepatite. $O$ fígado é o principal órgão que sintetiza o colesterol $^{21}$, então processos inflamatórios ou infecciosos que levam à disfunção deste órgão podem induzir a diminuição das concentrações plasmáticas desta variável. Os eqüinos soroprodutores da presente pesquisa tenderam a apresentar diminuição das concentrações de colesterol durante o processo de produção de plasmahiperimune, sugerindo que houve alteração da função hepática neste período.

A avaliação das concentrações de colesterol entre os grupos A e B, demonstrou que não houve diferença para esta variável durante a pesquisa $(p<0,9)$, sugerindo que os teores protéicos das dietas não interferiram na síntese de colesterol entre os grupos experimentais estudados. Concordando com a afirmação de Neves et al..$^{22}$ que afirmaram que a fonte de proteína na dieta de animais é mais importante do que o teor de proteína delas nas concentrações séricas de colesterol e triglicérides.

Os teores de triglicérides observados neste estudo quando comparados aos valores de referência ${ }^{19}(0,0452-0,4972 \mathrm{mmol} / \mathrm{L})$ foram maiores em apenas dois dias, na primeira fase no dia 58 para o grupo B e na segunda fase no dia 119 para ambos os grupos. Porém, quando comparados entre os grupos foi observado, na primeira fase, o aumento das concentrações de triglicérides do grupo $\mathrm{B}$ em relação ao $\mathrm{A}$, aos 58 dias $(\mathrm{p}<0,001)$ e, na segunda fase diminuição das concentrações de triglicérides do grupo $\mathrm{B}$ em relação ao grupo A nos dias 95 e $137(\mathrm{p}<0,04)$ e aumento no dia $109(\mathrm{p}<0,04)$ (Figura 2). Embora as variações deste metabólito foram distintas entre as fases da pesquisa, não foi possível determinar se houve interferência do teor protéico das dietas nestes resultados. Estudos determinando as concentrações séricas de colesterol e triglicérides, em animais principalmente ratos, tem sido realizados. ${ }^{23,24,25,26,27}$ Estes estudos comparam as concentrações destas variáveis em animais alimentados com rações à base de soja e animais alimentados com rações à base de caseína (respectivamente proteína vegetal e animal). Porém, nenhum estudo comparando as concentrações destas variáveis em animais alimentados com diferentes fontes ou diferentes teores de proteína vegetal foi encontrado. Mais estudos comparando as concentrações de variáveis como o colesterol e os triglicérides, são necessários para determinar se existe interferência da natureza da proteína vegetal nestas determinações.

A análise intragrupos indicou na

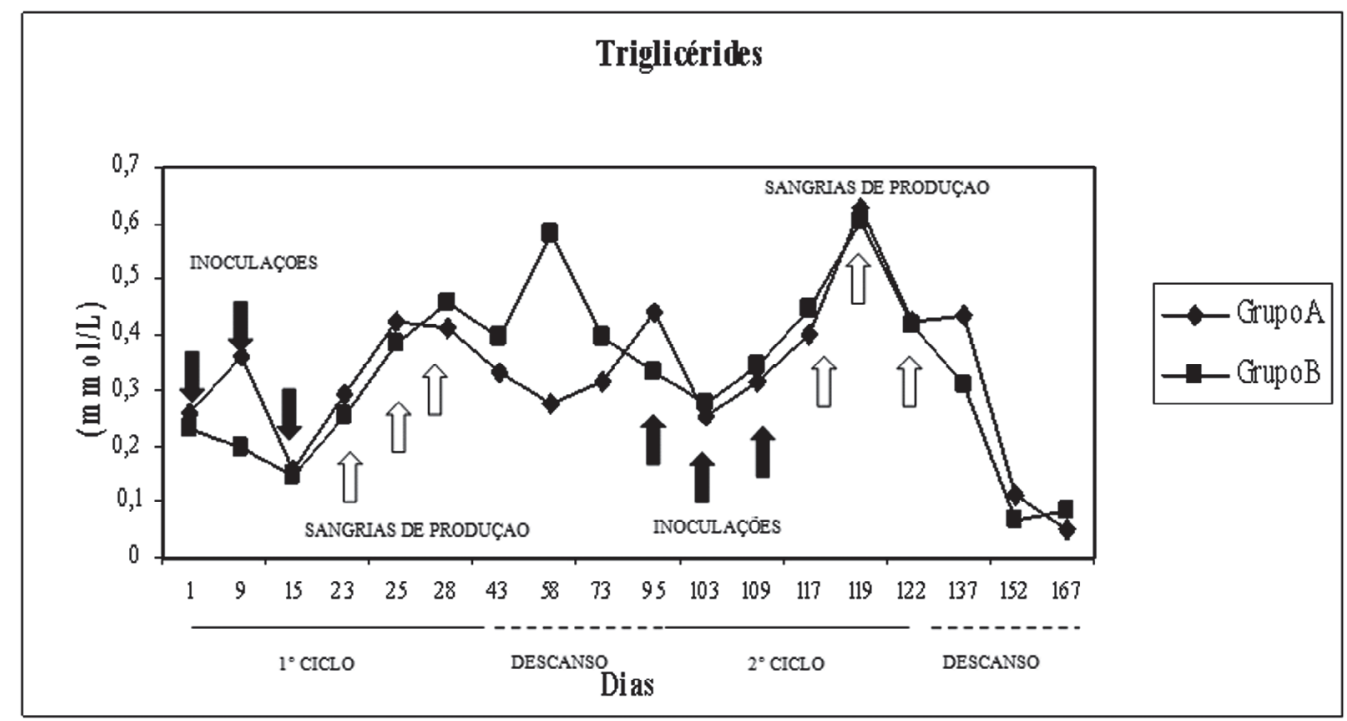

Figura 2 - Representação gráfica das concentrações séricas de triglicérides dos grupos A (concentrado com 15\% de proteína bruta) e B (concentrado com $22 \%$ de proteína bruta) 
primeira fase diminuição das concentrações de triglicérides tanto para o grupo A como para o B no dia 15 ( $\mathrm{p}<0,02$ para ambos), aumento das concentrações para o grupo A nos dias 25, 28 e $43(\mathrm{p}<0,005)$ e para o grupo B nos dias 25, 28, 43, 58 e 73 $(p<0,0001)$. Na segunda fase, houve diminuição das concentrações de triglicérides tanto para o grupo A como para o grupo B nos momentos dias 152 e 167 (respectivamente $\mathrm{p}<0,001$ e $\mathrm{p}<0,0001$ ); e aumento das concentrações para o grupo A nos dias 95, 117, 119, 122 e 137 $(\mathrm{p}<0,0001)$ e para o grupo B nos dias 95 , 109, 117, 119 e 122 ( $<<0,0001)$.

Esperava-se determinar a ocorrência do processo de lipidose nestes animais em decorrência das imunizações, contudo as fases de produção avaliadas apresentaram comportamentos muito distintos, não havendo a possibilidade de determinálo. Estudos com cavalos soroprodutores por períodos de tempo maiores são necessários para determinar a ocorrência desta enfermidade nesta categoria de animais.

\section{Conclusões}

Apesar de terem ocorrido significâncias entre os grupos A e B para as concentrações de triglicérides em determinados momentos, elas não foram suficientes para afirmar se os teores de proteína bruta dos concentrados interferiram nestes resultados. Mais pesquisas avaliando os dois grupos experimentais por um período de tempo maior são necessárias para determinar se o teor de $\mathrm{PB}$ nos concentrados fornecidos aos cavalos soroprodutores interfere nas concentrações séricas destas variáveis.

As concentrações de colesterol e triglicérides sofreram alterações durante o processo de produção de plasmahiperimune, evidenciadas através do aumento e/ou diminuição em suas concentrações, demonstrando-se muito sensíveis ao processo de produção de plasma-hiperimune.

\section{Agradecimentos}

À Fundação Butantan que concedeu auxílio financeiro para a colheita de material biológico e realização dos exames laboratoriais e, ao Instituto Butantan que permitiu a utilização dos seus animais para esta pesquisa.

\section{Serum evaluation of cholesterol and triglycerides of serum-producing horses fed concentrate with $15 \%$ or $22 \%$ of crude protein}

\section{Abstract}

The hyperimmune serum production in horses is still fundamental to obtain the serum used in the treatment of some diseases like tetanus and diphtery. In order to determine the benefit of the utilization of high-protein concentrate in serum-producing horses dietary of Butantan Institute, the serum concentrations of cholesterol and triglycerides were screened from a group of 32 anti-diphteric serum-producing horses. Those horses were distributed occasionally in two groups of 16 equines. The animals of group A were fed with a concentrate with $15 \%$ of crude protein (CP) and the animals of group B were fed with a concentrate with $22 \%$ of CP. The serum samples were obtained in two immunization periods, in moments previous to the antigen inoculation, before the bleeding of production and with a delay of 15, 30 and 45 days after the last bleeding. The serum concentrations of triglycerides were higher in group $B$ in day 58 of the first period $(p<0,001)$ and in the second period were higher in group A in days 95 and $137(\mathrm{p}<0,04)$ and in group B in day 109
Key words: Serum-producing horses. Crude protein. Cholesterol. Triglycerides. 
$(p<0,04)$. There was no difference between the groups for cholesterol serum concentrations. We concluded that although the triglycerides and cholesterol serum concentrations be sensitive to the process of anti-diphteric hyperimmune plasma production, the results found were not enough to affirm weather there is or not a benefit in the utilization of high-protein concentrate $(22 \% \mathrm{CP})$ in anti-diphteric serum-producing horses based on two periods of production.

\section{Referências}

1 BRAGA, A. Soros-vacinas alérgenos e imunígenos. Rio de Janeiro: Serviço de Informação Agrícola do ministério da Agricultura, 1943. p. 37-43.

2 GRAHAM-THIERS, P. M.; KRONFELD, D. S.; KLINE, K. A.; SKALAN, D. J.; HARRIS, P. A. Dietary protein and fat effects on protein status in arabian horses during interval training and repeated sprints. Journal of Equine Veterinary Science, v. 23, n. 12, p.554-559, 2003.

3 MILLER, P. A.; LAWRENCE, L. M. The effect of dietary protein level on exercising horses. Journal of Animal Science, v. 66, p. 2185-2192, 1988.

4 PATTERSON, P. H.; COON, C. N.; HUGHES, I. M. Protein requirements of mature working horses. Journal of Animal Science, v. 61, n. 1, p. 187-196, 1985.

5 GALVÃO, P. M.; ALMEIDA, F.Q.; OLIVEIRA, C. A.; LIMA, J. R. P. A.; VIEIRA, A. A; ADESE, B.; SANTOS, T. M. Avaliação de dietas para eqüinos de uso militar em atividade física moderada. Revista Brasileira de Zootecnia, v. 33, n. 6, p. 1492-1499, 2004.

$6 \mathrm{KLINE}, \mathrm{K}$. H. Horse nutrition and health. Horse feeds and feeding. Feedstuffs, v. 15, p. 48-51, 2004.

7 NATIONAL RESEARCH COUNCIL. Nutrient requirements of horses. 5th ed. Washington DC: NRCNAS, 1989. p. 7-9.

8 HOUSEHOLDER, D. Performance horses need protein, but not too much. Journal of Equine Veterinary Science, v. 16, n. 1, p. 40-42, 1996.

9 REY, L. Planejar e redigir trabalhos científicos. 2. ed. São Paulo: Edgard Blücher, 2003. p. 67-72.

10 GALLAGHER, K.; LEECH, J.; STOWE, H. Protein, energy and dry matter consumption by racing thoroughbreds: a field survey. Journal Equine Veterinary Science, v. 12, p. 43-48, 1992.

11 SOUTHWOOD, L.; EVANS, D.; BRYDEN, W.; ROSE, R. Nutrient intake of horses in Thoroughbred and Standarbred stables. Australian Veterinary Journal, v. 70, p. 164-168, 1993.

12 HINTZ, H. F. Nutrition and equine performance. The Journal of Nutrition, v. 124, n. 12 p. 2723S-2729S, 1994.

13 BIRGEL, E. H. Patologia clínica veterinária. In: BIRGEL, E. H.; BENESI, F. J. Patologia clínica veterinária. São Paulo: Sociedade Paulista de Medicina Veterinária,
1982. p. 2.

14 ALLAIN, C. C.; POON, L. S.; CHAIN, C. S. G.; RICHMOND, W.; FU, P. C. Enzimatic determination of total serum cholesterol. Clinical Chemistry, v. 20, p. 470-475, 1974.

15 FOSSATI, P.; PRENCIPE, L. Serum triglycerides determined colorimetrically with an enzyme that produces hydrogen peroxide. Clinical Chemistry, v. 28, p. 2077-2080, 1982

16 MINITAB. Statistical software, release $\mathbf{1 4}$ for windows. Pennsylvania: State College, 2003.

17 PETRIE, A.; WATSON, P. Statistics for veterinary and animal science. London: Blackwell Science, 1999. p. 138-139.

18 REY, F.; HALLEBEEK, J. M.; BEYNEN, A. C. Apparent digestibility of crude fiber in ponies fed either a low or high-protein diet. Journal Animal Physiology Animal Nutrition, v. 85, p. 251-254, 2001.

19 RADOSTITIS, O. M.; GAY, C. C.; BLOOD, D. C.; HINCHCLIFF, K. W. Clínica veterinária. Um tratado de doenças dos bovinos, ovinos, suínos, caprinos e eqüinos. Rio de Janeiro: Guanabara Koogan, 2002. p. 1648.

20 SAHAL, M.; ALTINTAS, A.; ARSLAN, H. H.; URAL, K.; AKSOY, E. Serum hepatitis associated with administration of tetanus toxin in serum producing horses and therapy. Revue Médicine Véterinaire, v. 155, n. 10, p. 476-482, 2004

21 MEYER, D. J.; COLES, E. H.; RICH, L. J. Veterinary laboratory medicine-interpretation and diagnosis. Philadelphia: W. B. Saunders, 1992. p. 56-68.

22 NEVES, L. B.; FREMERY, D. D.; KNUCKLES, B. E.; CHEOWTIRAKUL, C.; MILLER, M. W.; WEIR, W. C.; CLIFFORD, A. J. Effects of dietary protein from a variety of sources on plasma lipids and lipoproteins of rats. The Journal of Nutrition, v. 110, n. 4, p. 732-742, 1980.

23 BRANDSCH, C.; SHUKLA, A.; HIRCHE, F.; STANGL, G. I.; EDER, K. Effect of proteins from beef, pork, and turkey meat on plasma and liver lipids of rats compared with casein and soy protein. Nutrition, v. 22, p. 1162-1170, 2006.

24 FORSYTHE, W. A.; MILLER, E. R.; HILL, G. M.; ROMSOS, D. R.; SIMPSON, R. C. Effects of dietary protein and fat sources on plasma cholesterol parameters, LCAT activity and amino acid levels and on 
tissue lipid content of growing pigs. The Journal of Nutrition, v. 110, n. 12, p. 2467-2479, 1980.

25 SIHEM, M.; LOPEZ, S.; BLOND, J. P.; PROST, J.; BELLEVILLE, J. Highly purified soybean protein is not hypocholesterolemic in rats but stimulates cholesterol synthesis and excretion and reduces polyunsaturated fatty acid biosynthesis. The Journal of Nutrition, $v$. 128, n. 7, p. 1084-1091, 1998.

26 SIHEM, M.; PROST, J.; BELLEVILLE, J. Dietary protein level and origin (casein and highly purified soybean protein) affect hepatic storage, plasma lipid transport, and antioxidative defense status in the rat. Nutrition, $v$. 16, p. 368-375, 2000.

27 SIHEM, M.; PROST, J.; NARCE, M.; BELLEVILLE, J. VLDL Metabolism in rats is affected by the concentration and source of dietary protein. The Journal of Nutrition, v. 113, n. 12, p. 4102-4106, 2003. 